\title{
Specific Heats of Saturated and Compressed Liquid Propane*
}

\author{
Robert D. Goodwin \\ Center for Mechanical Engineering and Process Technology National Bureau of Standards, Boulder, Colorado \\ 80303
}

January 22, 1978

\begin{abstract}
Experimental specific heats for saturated liquid propane, along the coexistence path, have been determined from the triple-point temperature $(\sim 85 \mathrm{~K})$ to $289 \mathrm{~K}$. Specific heats for the compressed liquid at constant molal volume have been determined along isochores at nine different densities ranging from near the triple-point liquid density to about twice the critical-point density (at pressures up to 300 bar). Comparisons with previous experimental-and/or derived-data show agreement within combined uncertainties of about three percent. Key words: Constant volume; heat capacities; liquid; propane; saturated liquid; specific heats.
\end{abstract}

\section{List of Symbols}

Subscript $c$ refers to the critical point

$C_{o}(T) \quad$ heat capacity of the empty calorimeter, $\mathrm{J} / \mathrm{K}$

$C_{\sigma}(T) \quad$ specific heat for saturated liquid, $\mathrm{J} / \mathrm{mol} / \mathrm{K}$

$C_{v}{ }^{o}(T) \quad$ specific heat in ideal gas states, $\mathrm{J} / \mathrm{mol} / \mathrm{K}$

$C_{v}(\rho, T)$ isochoric specific heat, $\mathrm{J} / \mathrm{mol} / \mathrm{K}$

$C_{p}(\rho, T)$ isobaric specific heat, $\mathrm{J} / \mathrm{mol} / \mathrm{K}$

$\mathrm{J}$ the joule, $1 \mathrm{~N}-\mathrm{m}$

L the liter, $10^{-} 3 \mathrm{~m}^{3}$

mol 44.09721 grams of propane ( $C^{12}$ scale)

$\bar{N} \quad$ total moles of fluid in bomb plus capillary

$\bar{N}_{b} \quad$ moles of fluid in the calorimeter (bomb)

$P \quad$ pressure in bars, 1 bar $\equiv 10^{5} \mathrm{~N} / \mathrm{m}^{2}(1 \mathrm{~atm}=1.01325 \mathrm{bar})$

$Q \quad$ calorimetric heat input, J

$Q / \Delta T$ gross heat capacity (bomb + sample), $\mathrm{J} / \mathrm{K}$

$R \quad$ the gas constant, $8.31434(\mathrm{~J} / \mathrm{mol}) / \mathrm{K}$

$\rho \quad$ density, $\mathrm{mol} / \mathrm{L}$

$T \quad$ temperature, $\mathrm{K}(1968)$

$\Delta T \quad$ calorimeter temperature increment, $\mathrm{K}$

$V_{b}(T, P)$ volume of the calorimeter, $\mathrm{cm}^{3}$

\section{Introduction}

In a recent report on the thermodynamic properties of propane, we indicated the desirability for more accurate data for virtually all physical and thermal properties [8]. ${ }^{1}$ The present specific heat measurements serve to broaden the experimental data base and to confirm the work in [8] to within combined uncertainties of about three percent in specific heat data. They serve also in comparisons utilizing an equation of state for interpolations. It is anticipated that the present measurements will be incorporated with other new properties measurements in a revision of the thermodynamic tables in [8].

* This work was supported by the American Gas Association, Inc., 1515 Wilson Boulevard, Arlington, VA 22209.

${ }^{1}$ Figures in brackets indicate the literature references at the end of the paper.
Symbols and units are given in a list. Fixed-point constants, used in computations, are given in table 1. Figure 1 shows the densities, and temperature ranges of the nine experimental runs.

\begin{tabular}{|c|c|c|c|}
\hline & Triple Point & Boiling Point & Critical Point \\
\hline Temperature, K & 85.47 & 231.0679 & 369.80 \\
\hline Pressure, bar & $1.6609 \cdot 10^{-9}$ & 1.01325 & 42.3974 \\
\hline \multicolumn{4}{|l|}{ Density, mol/L } \\
\hline Vapor & $2.3373 \cdot 10^{-10}$ & 0.05479 & 4.96 \\
\hline Liquid & 16.620 & 13.1687 & 4.96 \\
\hline
\end{tabular}

\section{Experimental}

Apparatus, technique, and computational procedures have been fully described so often, in work on other substances, that we refer the reader to these publications, to avoid unnecessary repetition $[4,5,6,7,11,12,14,15,16]$.

In [5], for example, we gave an accounting of sources of uncertainty. For the present work we have considered only the sources of gross uncertainties, concluding that total uncertainty in each specific heat measurement must be set at about two percent. Nearly all comparisons, reported below, fall well within this figure.

For the present work on propane we have employed the same apparatus, methods, and computational procedures described in detail by Roder in his prior work on ethane [12], except for replacing the platinum resistance thermometer.

The propane is a commercial "research grade," specified to be 99.99 percent pure, with a trace of ethane. No further analysis was made.

For computation of saturated liquid specific heats, from observations on a two-phase sample at constant volume, it is 


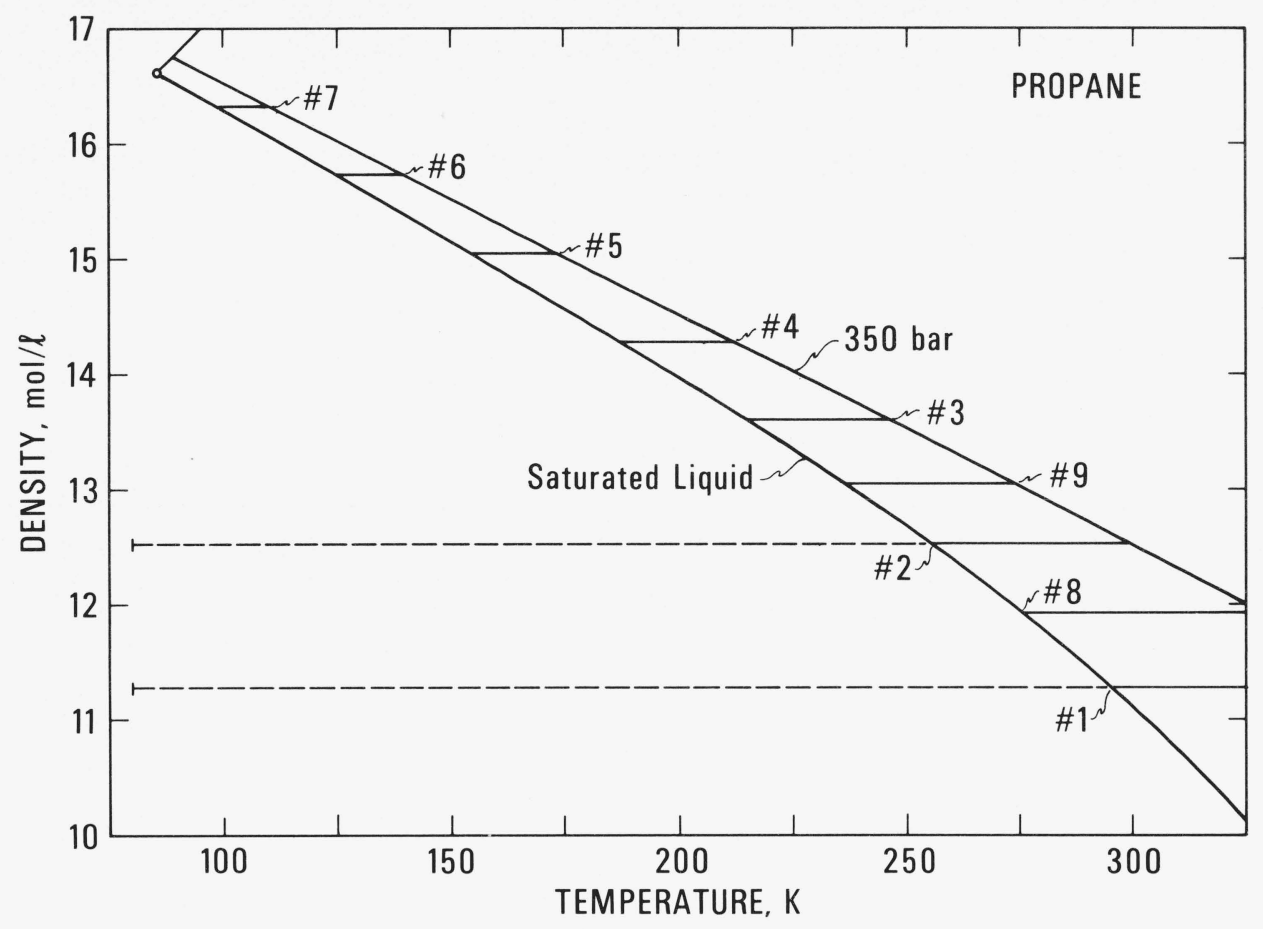

Figure 1. The $\rho$-T loci of experimental runs.

Table 2. Heat capacity of the empty calorimeter

\begin{tabular}{|c|c|c|c|c|c|c|c|c|c|c|c|c|c|c|c|c|c|}
\hline $\begin{array}{l}\text { Run } \\
\text { no. }\end{array}$ & $\begin{array}{l}\mathrm{T}_{\mathrm{av}}, \\
\mathrm{K}\end{array}$ & $\begin{array}{c}\Delta \mathrm{T}, \\
\mathrm{K}\end{array}$ & $\begin{array}{l}\text { Power, } \\
\text { watt }\end{array}$ & $\begin{array}{c}\text { Time, } \\
\text { sec }\end{array}$ & $\begin{array}{l}\text { Heat, } \\
\text { joule }\end{array}$ & $\begin{array}{l}\text { Heat Ca } \\
\text { Expt } 1 .\end{array}$ & $\begin{array}{l}., \mathrm{J} / \mathrm{K}, \\
\text { Calcd. }\end{array}$ & $\begin{array}{c}\text { Diff., } \\
\%\end{array}$ & $\begin{array}{l}\text { Run } \\
\text { no. }\end{array}$ & $\begin{array}{c}\mathrm{T}_{\mathrm{av}}, \\
\mathrm{K}\end{array}$ & $\begin{array}{c}\Delta \mathrm{T}, \\
\mathrm{K}\end{array}$ & $\begin{array}{l}\text { Power, } \\
\text { watt }\end{array}$ & $\begin{array}{c}\text { Time, } \\
\text { sec }\end{array}$ & $\begin{array}{l}\text { Heat, } \\
\text { joule }\end{array}$ & $\begin{array}{l}\text { Heat C } \\
\text { Expt } 1 .\end{array}$ & $\begin{array}{r}\text { y., J/K, } \\
\text { Calcd. }\end{array}$ & $\begin{array}{c}\text { Diff., } \\
\%\end{array}$ \\
\hline 701 & 90.338 & 2.556 & .16301 & 606.59 & 98.88 & 38.677 & 38.664 & .03 & 909 & 210.749 & 6.651 & .82845 & 605.75 & 501.83 & 75.458 & 75.408 & .07 \\
\hline 702 & 82.844 & 455 & .16261 & 73 & 53 & 40.138 & 40.146 & -.02 & 402 & 217.173 & 808 & .86052 & 602.82 & 80 & 210 & & .09 \\
\hline 101 & 83.566 & 3.759 & .25234 & 604.15 & 152.45 & 40.559 & 40.564 &. .01 & 1001 & 217.761 & 6.601 & .82893 & 606.95 & 503.12 & 76.213 & 76.208 & .01 \\
\hline 703 & 85.555 & 2.972 & .20591 & 601.68 & 123.89 & 41.685 & 41.692 & -.02 & 403 & 223.805 & 6.841 & .87126 & 603.18 & 525.53 & 76.824 & $76.8 E 2$ & -.05 \\
\hline 102 & 87.228 & 3.580 & .25197 & 605.37 & 152.53 & 42.603 & 42.617 & -.03 & 1002 & 224.611 & 7.303 & .92427 & 607.84 & 561.81 & 76.928 & 76.947 & -.02 \\
\hline 704 & 88.798 & 3.524 & .25418 & 602.72 & 153.20 & 43.471 & 43.465 & .01 & 404 & 230.399 & 6.766 & .87076 & 602.42 & 524.56 & 77.534 & 77.540 & -.01 \\
\hline 103 & 91.529 & 5.042 & .37435 & 604.78 & 226.40 & 44.901 & 44.899 & 0.00 & 1003 & 231.761 & 7.202 & .92299 & 606.18 & 559.50 & 77.690 & 77.675 & .02 \\
\hline 705 & 92.988 & 4.871 & .36651 & 606.73 & 222.37 & 45.650 & 45.643 & .02 & 405 & 236.925 & 6.702 & .87011 & 602.12 & 523.91 & 78.167 & 78.178 & -.01 \\
\hline 104 & 97.307 & 6.539 & .51730 & 603.52 & 312.26 & 47.752 & 47.759 & -.01 & 1004 & 238.818 & 7.131 & .92259 & 605.94 & 559.03 & 78.390 & & .04 \\
\hline 706 & 98.526 & 6.230 & .49924 & 603.32 & 301.20 & 48.344 & 48.334 & .02 & 406 & 243.368 & 6.649 & .86944 & 602.18 & 523.56 & 78.742 & 78.779 & -.05 \\
\hline 105 & 103.637 & 6.170 & .51713 & 604.19 & 312.44 & 50.640 & 50.641 & 0.00 & 1005 & 245.800 & 7.059 & .92145 & 605.37 & 557.81 & 79.022 & 78.998 & .03 \\
\hline 801 & 105.231 & 5.851 & .49698 & 604.37 & 300.36 & 51.331 & 51.327 & .01 & 407 & 249.749 & 6.588 & .86859 & 601.46 & 522.48 & 79.313 & & -.04 \\
\hline 106 & 109.624 & 5.859 & .51672 & 602.45 & 311.30 & 53.132 & 53.140 &. .02 & 1006 & 252.712 & 7.002 & .92116 & 605.91 & 558.14 & 79.710 & 79.604 & .13 \\
\hline 802 & 111.358 & 6.458 & .57453 & 605.22 & 347.71 & 53.846 & 53.826 & .04 & 408 & 256.060 & 6.547 & .86835 & 602.43 & 523.12 & 79.902 & 79.888 & .02 \\
\hline 107 & 115.329 & 5.621 & .51600 & 602.63 & 310.98 & 55.323 & 55.334 & -.02 & 1007 & 259.571 & 6.952 & .92 & 606.06 & 557 & 28 & 79 & .06 \\
\hline 803 & 117.650 & 6.186 & .57406 & 605.50 & 347.60 & 56.189 & 56.177 & .02 & 409 & 262.315 & 6.495 & .86799 & 602.34 & 522.83 & 80.498 & 80.402 & .12 \\
\hline 108 & 120.821 & 5.441 & .51562 & 604.71 & 311.80 & 57.308 & 57.285 & .04 & 1008 & 266.382 & 6.902 & .91995 & 605.97 & 557.46 & 80.771 & 80.726 & .06 \\
\hline 804 & 123.681 & 5.945 & .57394 & 603.57 & 345.41 & 58.268 & 58.242 & .04 & 410 & 268.499 & 6.464 & 46 & 603.34 & 523.37 & 80.967 & 80.891 & .09 \\
\hline 201 & 127.052 & 5.236 & .51380 & 604.54 & 310.61 & 59.318 & 59.322 & -.01 & 1101 & 271.535 & 6.878 & .92054 & 605.61 & 557.49 & 81 & 81 & -.09 \\
\hline $80 \%$ & 129.504 & 5.771 & .57352 & 604.76 & 346.91 & 60.108 & 60.076 & .05 & 501 & 274.806 & 6.438 & .86515 & 606.30 & 524.54 & 81.476 & 81.372 & .13 \\
\hline 202 & 132.158 & 5.077 & .51313 & 602.00 & 308 & 60.848 & 60.863 & -.03 & 1102 & 278.340 & & & & & & & -.02 \\
\hline 806 & 135.156 & 5.615 & .57339 & 604.48 & 346.60 & 61.725 & 61.719 & .01 & 502 & 280.917 & 6.366 & .86434 & 602.10 & 520.42 & 81 & 81 & -.09 \\
\hline 203 & 137.118 & 4.955 & .51256 & 601.46 & 308.35 & 62.232 & 62.259 & -.04 & 1103 & 285.105 & 6. & .9 & 605.82 & 555. & 82 & & -.04 \\
\hline 807 & 140.655 & 5.481 & .57314 & 604.37 & 346.39 & 63.194 & 63.198 & -.01 & 503 & 286.958 & 6.315 & .86384 & 601.14 & 519.29 & 82.224 & 82.253 & -.04 \\
\hline 204 & 141.960 & 4.848 & .51196 & 601.05 & 307.72 & 63.477 & 63.533 & -.09 & 1104 & 291.872 & & & & & & & -.05 \\
\hline 808 & 146.029 & 5.379 & .57288 & 606.25 & 347.31 & 64.564 & 64.541 & .03 & $50_{4}$ & 292.930 & 6.272 & .86347 & 600.25 & 518.30 & 82.633 & 82.666 & -.04 \\
\hline 205 & 146.696 & 4.759 & .51189 & & & 6 & & -0.05 & 1105 & & & & & & & & -.08 \\
\hline 206 & 151.345 & 4.680 & $.511 \div 9$ & 601.59 & 307.71 & 65.744 & 65.779 & -.05 & 505 & 298.868 & 6.244 & .86290 & 600.99 & 518.59 & 83.052 & 83.064 & -.02 \\
\hline 901 & 155.708 & 7.479 & .82540 & 604.43 & 498.90 & & & -.04 & 501 & & & 1.07 & & & & & -.15 \\
\hline 207 & 155.924 & 4.637 & .51113 & 605.41 & 309.44 & 40 & 66.779 & -.06 & 506 & 304.748 & 6.213 & .86255 & 601.32 & 518 & 83.476 & 83.448 & .03 \\
\hline 208 & 161.159 & 6.001 & .67697 & 601.59 & 407.26 & 67.867 & 67.853 & .02 & 1106 & 305.362 & 6.742 & .92764 & 606.38 & 56 & 83 & 83.487 & -06 \\
\hline 902 & 163.013 & 7.288 & .82402 & 603.21 & 497.06 & 68.205 & 68.216 & -.02 & 602 & 306.746 & 7.721 & 1.06883 & 602.60 & 644.07 & 83.422 & 83.575 & -.18 \\
\hline 209 & 167.036 & 5.933 & .67651 & 604.96 & & & & 0.00 & 1107 & 312.788 & 8.200 & 1.13382 & & & & & -.05 \\
\hline 903 & 170.156 & 7.169 & .82288 & 605.18 & 498.81 & 69.575 & 69.545 & .04 & 603 & 313.758 & 6.412 & .88694 & 606.46 & 537.89 & 83.889 & 84.015 & -.15 \\
\hline 301 & 175.056 & 5.811 & .67834 & 602.19 & & 70.355 & & -.05 & 604 & 320.100 & 6.375 & & & $537.2 \pi$ & 84.269 & & -.16 \\
\hline 304 & 177.155 & 7.006 & .82346 & 601.90 & 495.64 & 70.749 & 70.743 & .01 & 1108 & 320.907 & 8.126 & 1.1 & 605.79 & & & & .03 \\
\hline 302 & 181.421 & 7.166 & $.850+2$ & 601.72 & & 71.413 & 71.428 & -.02 & 605 & 326.414 & 6.350 & & & & & 84 & -.23 \\
\hline 905 & 184.033 & 6.955 & .82342 & 606.98 & 499.80 & 71.863 & 71.833 & .04 & 1109 & 328.976 & 8.077 & 1.13242 & & 686.27 & & & .05 \\
\hline 30 & & 7. & .84965 & 601.40 & 510.98 & 72.471 & & -.02 & 606 & 332.705 & 6.317 & .88560 & & & & & -10 \\
\hline 906 & 190.824 & 6.851 & .82311 & 606.56 & 499.26 & 72.871 & 72.833 & .05 & 1201 & 335.011 & 6.544 & .92627 & 603.17 & 55 & & 85. & .12 \\
\hline 304 & 195.261 & 6.975 & .84912 & 603.09 & 512.10 & 73.423 & 73.450 & -.04 & 607 & 339.007 & 6.274 & .88521 & 606.58 & & & 85. & .10 \\
\hline 907 & 197.541 & 6.816 & .82945 & 606.54 & 503.09 & 73.814 & 73.756 & .08 & 1202 & 341.557 & & & & & & & .22 \\
\hline 305 & 202.027 & & .84849 & 602.03 & 51 & 344 & 74.340 & .01 & 608 & 345.347 & 6.228 & .88 & 606.32 & $=\pi$ & 86.115 & 85.838 & .32 \\
\hline 908 & 204.197 & 6.734 & .82923 & 606.28 & 502.75 & 74.657 & 74.614 & .06 & & & & & & & & & \\
\hline 401 & 210.602 & 6.700 & .83869 & 602.26 & 505.11 & 75.385 & 75.390 & .01 & $N P=$ & $88, F M$ & $C T=$ & I & & & & & \\
\hline
\end{tabular}


necessary to have accurate formulations of the vapor pressures, and of the saturated liquid densities. Because experimental specific heats at constant pressure are available from another source [13], comparisons with our results demand use of an equation of state. The equation of state used here [9] is a slight modification of that reported in [8], obtained by use of the new vapor pressures below the boiling point, derived at the end of that report.

\section{Heat Capacity of the Empty Calorimeter}

The heat capacity of the empty calorimeter must be subtracted from all observations on a sample. Data on the empty calorimeter are presented in table 2, because they indicate the precision obtained over the very long temperature range of the propane measurements. A new formulation for these data has been developed, and a "best" value has been selected for the number of terms, in the expression

$$
100 / C_{o}=\sum_{i=1}^{n} A_{i} \cdot x^{(i-1)}, n=6,
$$

where $x \equiv 100 / T$, and -

$$
\begin{aligned}
& A_{1}=0.81790976 \quad A_{4}=4.50479912 \\
& A_{2}=\begin{array}{llll}
1.7893 & 2156 \quad A_{5}=-2.5192 \quad 8428
\end{array}
\end{aligned}
$$

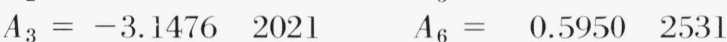

This formula yields a constant for $C_{o}$ at very high temperatures, and a behavior approaching $T^{5}$ as $T \rightarrow 0$.

\section{Results for Saturated Liquid}

The calorimeter $(T, P)$ loading conditions for the sample in each experimental run are presented in table 3 . The density is obtained from the equation of state given in [9]. The total amount of sample, $\bar{N}$, includes the relatively small amount residing in the capillary tube. The equation of state originates on the saturated liquid boundary, and is extrapolated at temperatures below $170 \mathrm{~K}$ where no $P$ - $\rho$ - $T$ compressibility data exist. In this region the density is relatively insensitive to pressure, but derivatives of the $P(\rho, T)$ surface, used to intercompare $C_{v}$ with $C_{p}$ data, must become increasingly uncertain with diminishing temperature.

Results for specific heats of saturated liquid propane $\left(C_{\sigma}\right)$ in experimental runs numbers 1 and 2 are presented in table 4 and in figure 2. Pressures here are the vapor pressures. The corrections in columns 10 and 11 are: A, for work done in expanding the calorimeter and in pumping fluid into the capillary tube and B, for the heat of vaporization and heat absorbed by the vapor [5]. Column 12 gives the experimental results. The "calculated" value in column 13 is from a formulation of older experimental and recently derived data in [8]. The last two columns give $C_{v}$ and $C_{p}$ derived from the $C_{\sigma}$ data of column 12 by methods of [8] with the equation of state of [9].

In the present work we did not succeed in freezing the sample at temperatures below the reported triple point of 85.47 K, due possibly to the viscous behavior of the fluid, the small temperature difference of only $5 \mathrm{~K}$ below the triplepoint, and a time of no more than six hours at this temperature. Deviations in column 14 of table 4 are within our anticipated uncertainties.

The following fitting function for $C_{\sigma}(T)$ was developed for all available data $\left(x \equiv T / T_{c}\right)$,

$$
C_{\sigma}(T)=A_{1} \cdot x /(1-x)^{\epsilon}+\sum_{i=2}^{n} A_{i} \cdot x^{i-2}
$$

in which $\epsilon=0.7$, and $n=5$. In table 5, however, we apply

\begin{tabular}{|c|c|c|c|c|c|c|c|}
\hline \multirow{2}{*}{ Run } & \multirow{2}{*}{$T, K$} & \multirow{2}{*}{$P$, bar } & \multirow{2}{*}{$\rho, \mathrm{mol} / \mathrm{L}$} & \multirow{2}{*}{$\mathrm{V}_{b}, c m^{3}$} & \multirow{2}{*}{$\bar{N}, \mathrm{~mol}$} & \multicolumn{2}{|c|}{ Coexistence Conditions ${ }^{a}$} \\
\hline & & & & & & T.K & $\rho, \mathrm{mol} / \mathrm{L}$ \\
\hline 1 & 294.976 & 11.442 & 11.292 & 73.324 & 0.8288 & 294.150 & 11.303 \\
\hline 2 & 254.544 & 15.372 & 12.577 & 73.196 & 0.9213 & 252.415 & 12.591 \\
\hline 3 & 214.940 & 16.541 & 13.620 & 73.071 & 0.9960 & 212.889 & 13.635 \\
\hline 4 & 187.209 & 18.600 & 14.302 & 72.988 & 1.0447 & 185.051 & 14.318 \\
\hline 5 & 155.086 & 20.047 & 15.051 & 72.896 & 1.0980 & 153.309 & 15.067 \\
\hline 6 & 125.098 & 19.598 & 15.736 & 72.814 & 1.1467 & 123.602 & 15.752 \\
\hline 7 & 99.123 & 19.463 & 16.325 & 72.753 & 1.1885 & 97.825 & 16.340 \\
\hline 8 & 275.574 & 14.372 & 11.954 & 73.263 & 0.8766 & 273.712 & 11.967 \\
\hline 9 & 236.045 & 10.535 & 13.064 & 73.131 & 0.9562 & 234.541 & 13.077 \\
\hline
\end{tabular}
it only to our results, finding-

$$
\begin{array}{lrlr}
A_{1}= & -1.77942 & A_{4}= & -100.24355 \\
A_{2}= & 77.12878 & A_{5}= & 135.42504 \\
A_{3}= & 48.01034 & &
\end{array}
$$

TABLE 3. Loading conditions for the samples

\footnotetext{
${ }^{a}$ For calorimeter full of liquid.
} 


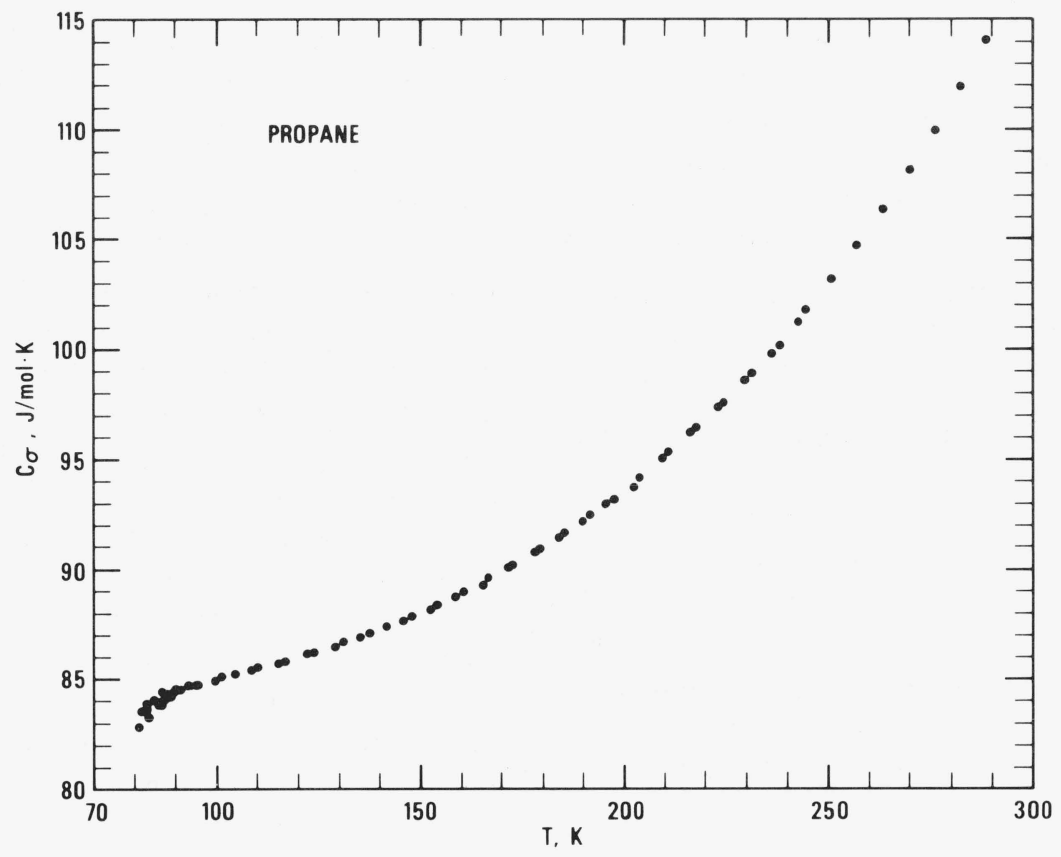

Figure 2. Specific heats for saturated liquid.

The rms relative deviation for our selected 76 data points is $0.13 \%$. Because $A_{1}$ is negative, this formulation should not be extrapolated above $290 \mathrm{~K}$.

In table 6, we give all available data for equation (2). These include: ID = 1, Dana [2]; ID = 2, Kemp [10]; ID = 8, Cutler [1]; and ID $=30$ for data derived from $C_{p}$ data of Yesavage [13] via our equation of state in [8]. The coefficients for this extended data set are-

$$
\begin{array}{llr}
A_{1}=6.63584 & A_{4}= & -19.92150 \\
A_{2}=80.76732 & A_{5}= & 51.18785 \\
A_{3}=8.27472 & &
\end{array}
$$

The rms relative deviation for 133 selected data is 0.29 percent. In tables 5 and 6 the column "Wt." gives the leastsquares weighting for that point.

\section{Results for Compressed Liquid}

Table 7 presents results in column 11 for the single-phase specific heats $C_{v}(\rho, T)$ of propane in nine experimental runs. These are shown in figure 3 . The smooth curve corresponds to extrapolation to the coexistence boundary. As the derivative $(\partial P / \partial \rho)_{T}$ for compressed liquid is large, the estimated pressures in column 4 become increasingly uncertain with decreasing temperatures. The correction in column 10 is for work done in expanding the calorimeter. The "calculated" value in column 12 is from the specific heats $C_{p}$ of Yesavage [13] via our equation of state [9] by the methods of [8].
Deviations in the last column fall within our estimate of combined uncertainties of about 3 percent. Our anticipated

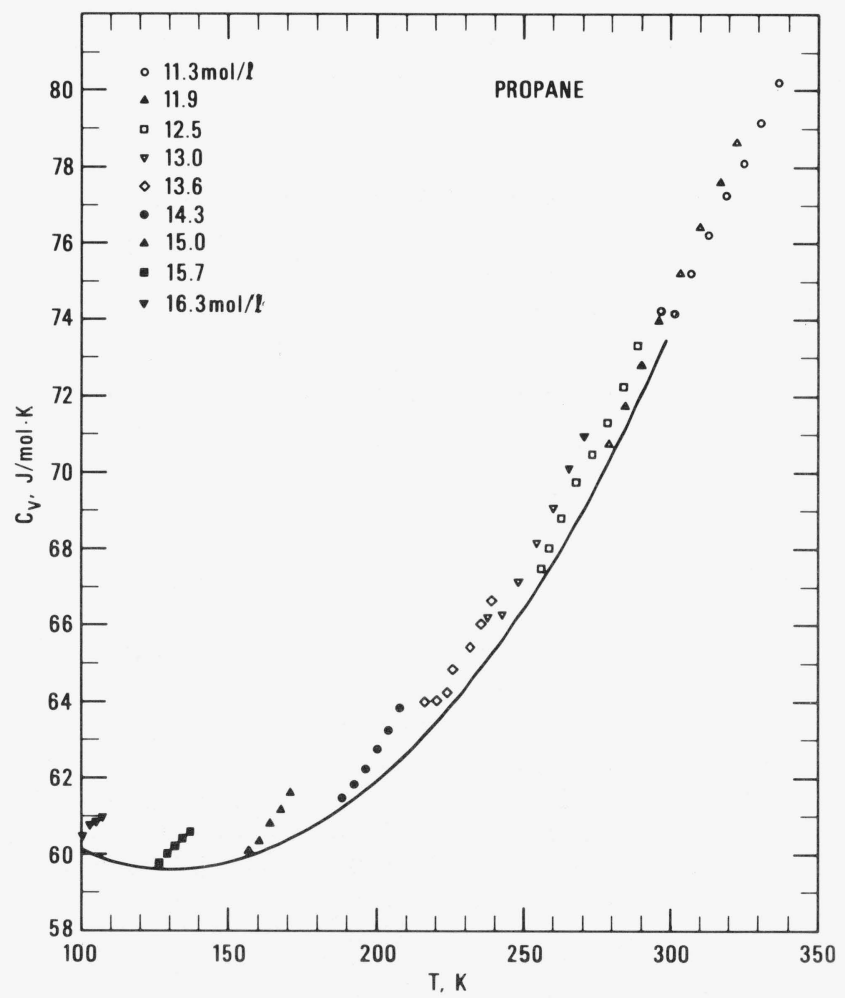

Figure 3. Specific heats for compressed liquid. 
increase of deviations at the lowest temperatures is seen at the bottom of table 7 .

Table 8 serves as an extension of table 7 to give "experimental" $C_{p}(\rho, T)$ data computed from the $C_{v}(\rho, T)$ data of table 7, column 11, by means of the equation of state [9]. The "calculated" results in table 8 again are from Yesavage $C_{p}(\rho, T)$ data [13], interpolated by means of the equation of state [9].

\section{Behavior of Reduced $C_{v}$ Data}

Diller has presented an examination of the behavior of available $C_{v}$ data for many substances, in a search for criteria of consistency [3]. In particular, he extrapolated data to the coexistence boundary and plotted reduced specific heats $\left[C_{v}\right.$ - $\left.C_{v}^{o}\right] / R$ vs. reduced density. Additional data for various substances subsequently were plotted in these coordinates by Younglove [16].

As a consistency test for present results on propane we present the reduced specific heats in table 9. Ideal gas specific heats $C_{v}^{o}$ are from the formulation in [8]. The first line for each run in table 9 gives results extrapolated to the coexistence boundary.

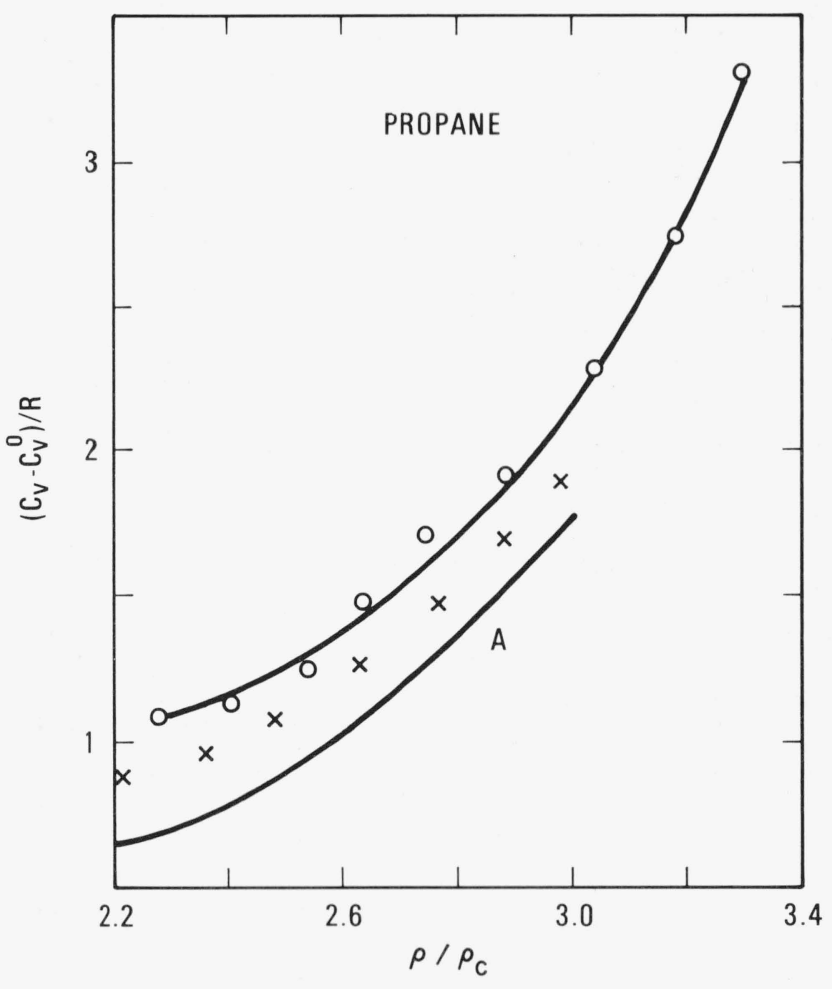

Figure 4. Reduced specific heats at coexistence.
Figure 4 shows present results. Open circles and the upper curve are for propane. The lower curve, marked A, is taken from figure 6 by Younglove [16]. It represents data for argon, krypton, oxygen, fluorine, and methane within experimental uncertainties. The points symbolized by $x$ are for ethane, as computed but not published by Roder [12]. At a reduced density near 3.0 (run number 5 ), the difference of about 0.5 in $\left(C_{v}-C_{v}^{o}\right) / R$ between propane and curve $\mathrm{A}$ corresponds to $4 \mathrm{~J} / \mathrm{mol} / \mathrm{K}$, or a difference of about $7 \%$ in the value $C_{v}=59.78 \mathrm{~J} / \mathrm{mol} / \mathrm{K}$ for propane (run number 5 ) in table 9. As our comparisons with Yesavage $C_{p}$ data [13] are much closer than $7 \%$, the higher values for propane in figure 4 probably are real.

The uniform increase of these residual specific heats with increasing asymmetry of molecular shape, from methane through propane, suggests hindered rotation of the asymmetric molecules in the dense (and viscous) liquid at low temperatures.

\section{References}

[1] Cutler, A. J. B., and Morrison, J. A., Trans. Faraday Soc. 61, 429 (1965).

[2] Dana, L. I., Jenkins, A. C., Burdick, J. N., and Timm, R. C., Refrig. Eng. 12, No. 12, 387 (June 1926).

[3] Diller, D. E., Cryogenics 11, No. 3, 186 (June 1971).

[4] Goodwin, R. D., J. Res. Nat. Bur. Stand. (U.S.) 65C, (Eng. and Instr.), No. 4, 231-243 (Oct.-Dec. 1961).

[5] Goodwin, R. D., and Weber, L. A., J. Res. Nat. Bur. Stand. (U.S.) 73A, (Phys. and Chem.), No. 1, 1-13 (Jan.-Feb. 1969).

[6] Goodwin, R. D., and Weber, L. A., J. Res. Nat. Bur. Stand. (U.S.) 73A, (Phys. and Chem.), No. 1, 15-24 (Jan.-Feb. 1969).

[7] Goodwin, R. D., and Prydz, R., J. Res. Nat. Bur. Stand. (U.S.) 74A, (Phys. and Chem.), No. 4, 499-505 (July-Aug. 1970).

[8] Goodwin, R. D., Provisional Thermodynamic Functions of Propane, from 85 to $700 \mathrm{~K}$ at Pressures to 700 Bar, Nat. Bur. Stand. (U.S.), Interagency Report NBSIR 77-860 (July 1977).

[9] Goodwin, R. D., The Nonanalytic Equation of State for Pure Fluids Applied to Propane, to be presented at Symp. on Equations of State in Engineering and Research, 176th National Meeting, American Chemical Society, Miami Beach, Florida, September 10-15, 1978.

[10] Kemp, J. D., and Egan, C. J., J. Am. Chem. Soc. 60, No. 7, 1521 (Jul 1938).

[11] Prydz, R., and Goodwin, R. D., J. Res. Nat. Bur. Stand. (U.S.) 74A, (Phys. and Chem.), No. 5, 661-665 (Sept.-Oct. 1970).

[12] Roder, H. M., J. Res. Nat. Bur. Stand. (U.S.) 80A, (Phys. and Chem.), No. 5, 6, 739-759 (Sept.-Dec. 1976).

[13] Yesavage, V. F., Katz, D. L., and Powers, J. E., J. Chem. Eng. Data 14, No. 2, 197 (Apr 1969).

[14] Younglove, B. A., and Diller, D. E., Cryogenics 2, No. 5, 283 (Sep 1962).

[15] Younglove, B. A., and Diller, D. E., Cryogenics 2, No. 6, 348 (Dec 1962).

[16] Younglove, B. A., J. Res. Nat. Bur. Stand. (U.S.) 78A, (Phys. and Chem.), No. 3, 401-410 (May-June 1974). 
Table 4. Experimental data for saturated liquid

\begin{tabular}{|c|c|c|c|c|c|c|c|c|c|c|c|c|c|c|c|}
\hline Run & $\mathrm{T}_{\text {av }}$, & $\rho_{\ell}$, & $\mathrm{P}$, & $\mathrm{N}_{\mathrm{b}}$, & $\mathrm{V}_{\mathrm{b}}$, & & & $\mathrm{C}_{\mathrm{O}}$, & r., & $\mathrm{J} / \mathrm{mol} / \mathrm{K}$, & $\mathrm{C}_{\sigma}$, & $\mathrm{ol} / \mathrm{K}$ & Diff & $\mathrm{C}_{\mathrm{v}}$ & $\mathrm{C}_{\mathrm{p}}$ \\
\hline no. & K & $\mathrm{mol} / \mathrm{L}$ & bar & mo1 & $\mathrm{cm}^{3}$ & $\mathrm{~K}$ & $\mathrm{~J} / \mathrm{K}$ & $\mathrm{J} / \mathrm{K}$ & A & B & Expt 1. & Calcd. & $\%$ & $\mathrm{~J} / \mathrm{mol} / \mathrm{K}$ & $/ \mathrm{mol} / \mathrm{K}$ \\
\hline 101 & 81.053 & 16.720 & 0.000 & . 3288 & 72.702 & .486 & 107.756 & 39.092 & 0.000 & 0.000 & 82.85 & 83.82 & -1.17 & 58.75 & 82.85 \\
\hline 102 & 81.756 & 6.704 & 0.000 & .8283 & 72.703 & .930 & 108.802 & & 0.000 & 0.000 & 83.61 & .86 & -.30 & .45 & 61 \\
\hline 103 & 82.677 & 16.683 & 0.000 & 3233 & 72.705 & .923 & 109.372 & 40.049 & 0.000 & & 83.65 & 83.0 & -.31 & & \\
\hline 104 & 83.593 & 16.663 & 0.000 & .8288 & 72.707 & .920 & 109.621 & 40.579 & .000 & 00 & 83.31 & 83.95 & -.77 & & \\
\hline 105 & 84.568 & 16.640 & 0.000 & .3238 & 72.708 & 1.039 & 110.624 & 41.136 & 0.000 & 0.000 & 83.84 & 84.00 & -.18 & 59.43 & 83.84 \\
\hline 106 & 85.598 & 16.617 & 0.000 & .3288 & 72.710 & 1.033 & 111.290 & 41.716 & 0.000 & 0.000 & 83.95 & 84.05 & -.12 & 59.44 & 83.95 \\
\hline 107 & 86.622 & 16.594 & 0.000 & .3292 & 72.712 & 1.024 & 112.143 & 42.284 & 0.000 & & 84.29 & 84.10 & .23 & 59.70 & 84.29 \\
\hline 108 & 86.336 & 16.589 & 0.000 & .8288 & 72.713 & 1.030 & 111.863 & 42.402 & 0.000 & 0.0 .00 & 83.81 & 84.11 & -.36 & 59.20 & 83.81 \\
\hline 109 & 87.856 & $16.56 €$ & 0.000 & .8288 & 72.715 & 1.022 & 112.699 & 42.959 & 0.000 & 0.000 & 84.15 & 84.16 & -.02 & 59.45 & 84.15 \\
\hline 110 & 88.871 & 16.543 & 0.000 & .8288 & 72.716 & 1.016 & 113.262 & 43.505 & 0.000 & 0.000 & 84.17 & 84.22 & -.05 & 59.38 & 84.17 \\
\hline 111 & 89.879 & 16.520 & 0.000 & .3288 & 72.718 & 1.008 & 114.052 & 44.039 & 0.000 & 0.000 & $8+.48$ & 84.27 & .25 & 59.60 & 84.48 \\
\hline 112 & 91.366 & 16.486 & 0.000 & .8288 & 72.721 & 1.970 & 114.875 & 44.815 & 0.000 & 00 & $8+.54$ & 84.34 & .23 & 59.54 & 84.54 \\
\hline 113 & 93.321 & 16.442 & 0.000 & .8288 & 72.725 & 1.950 & 116.033 & 45.8 & 0.000 & 0.000 & $8+.73$ & 84.45 & .34 & .58 & 73 \\
\hline 114 & 95.750 & 15.387 & 0.000 & .8288 & 72.730 & 3.708 & 117.236 & 47.011 & 0.000 & 0.000 & $8+.73$ & 84.57 & .19 & 59.39 & 84.73 \\
\hline 115 & 99.797 & 16.295 & 0.000 & .0288 & 72.739 & 4.400 & 119.322 & 48.923 & 0.000 & & 84.94 & 84.79 & .18 & 59.31 & 34.94 \\
\hline 116 & 104.646 & 16.185 & 0.000 & .3288 & 72.749 & 5.317 & 121.726 & 51.076 & 0 & 0 & 85.25 & 85.06 & .22 & 59.25 & 85.25 \\
\hline 117 & 110.300 & 16.056 & 0.000 & .8288 & 72.762 & 6.008 & 124.296 & 53.409 & 0.000 & 00 & 85.53 & 85.39 & .17 & 18 & .53 \\
\hline 118 & 116.889 & 15.905 & 0.000 & .9288 & 72.777 & 7.194 & 127.025 & 55.904 & 0.000 & 0.000 & 85.81 & & .03 & & 81 \\
\hline 119 & 124.009 & 15.742 & 0.000 & .8288 & 72.795 & 7.034 & 129.793 & 58.349 & 0.000 & -.001 & 86.20 & 86.25 & -.05 & 59.04 & 86.20 \\
\hline 120 & 131.003 & 15.582 & 0.000 & .3288 & 72.812 & 6.947 & $132.36^{\circ}$ & 60.524 & 0.000 & -.0 & 86.69 & 86.73 & -.05 & 59.15 & 85.69 \\
\hline 121 & 137.8 & 15.424 & .001 & .9288 & 72.830 & 6.830 & 134.681 & 62.463 & 0.0 & -.0 & 87.14 & 23 & -.11 & & 87.14 \\
\hline 122 & 145.757 & 15.242 & .002 & .3288 & 72.851 & $\epsilon .679$ & $137 \cdot 151$ & 64.476 & 0.000 & -.007 & $8 ? .68$ & 87.85 & -.19 & 59.41 & 87.68 \\
\hline 123 & 152.350 & 15.089 & .004 & . 9288 & 72.869 & 6.559 & 139.075 & 66.004 & 0.000 & -.01 & $8 \lesssim .1 \epsilon$ & 88.41 & -.25 & $59.5^{7}$ & 83.16 \\
\hline 124 & 158.858 & 14.937 & .008 & .9289 & 72.988 & 6.524 & 140.980 & 67.389 & & & 80.7 & & -.25 & & 77 \\
\hline 125 & 165. & 14.786 & .014 & .8288 & 72.906 & $6.4+0$ & $1+2.693$ & 68.654 & 100 & 34 & 89.30 & 2 &. .35 & 0 & .30 \\
\hline 126 & 171.647 & 14.637 & .025 & .8238 & 72.924 & 6.356 & 144.530 & 69.303 & 0.000 & -.051 & 90.11 & 90.27 & -.18 & 60.50 & 90.11 \\
\hline 127 & 179.354 & 14.454 & .048 & .8288 & $72.94^{-}$ & $6.2^{>3}$ & 140.499 & 71.100 & -.001 & -.0 & & 91.13 & -.25 & 61.01 & 90.91 \\
\hline 128 & 185.534 & 14.306 & .077 & .3288 & 72.965 & $6.2 n 3$ & 148.120 & 72.060 & -.001 & -.1 & 91.67 & 91.86 & -.21 & 61.46 & 91.68 \\
\hline 129 & 191.643 & 14.159 & .117 & .8288 & 72.983 & 6.132 & 149.703 & 72.949 & -.0 & - . & 92.48 & 92.64 & -.17 & 93 & .50 \\
\hline 130 & 197.586 & $1+.012$ & .174 & .8288 & 73.001 & 6.076 & $1 \equiv 1.161$ & 73.775 & -.002 & -.159 & 93.21 & 93.46 & -.26 & 62.31 & 93.24 \\
\hline 131 & 204.154 & 13.853 & .258 & .8288 & 73.021 & 7.001 & 152.785 & 74.608 & -.002 & -.1 & 94.13 & 94.39 & -.27 & 62.83 & 94.17 \\
\hline 132 & 211.041 & 3.681 & .380 & .8285 & .042 & $6.9 ? 3$ & 154.688 & 75.442 & -.0 & -.2 & 95.39 & 95.45 & -.06 & 63.62 & 95.45 \\
\hline 133 & 217. & 13.510 & .543 & .8288 & .064 & 6.859 & 156.350 & 76.219 & $-.00 \rightarrow$ & -.255 & 96.43 & 96.58 & -.16 & & 96.51 \\
\hline 134 & 224.592 & 13.337 & .754 & .3288 & 73.085 & $E .787$ & 158.027 & 76.945 & -.005 & -.274 & 47.55 & 97.77 & -.22 & 64.75 & 97.67 \\
\hline 135 & 231.245 & 13.164 & 1.021 & .8288 & .106 & 6.693 & 159.827 & 77.624 & -.007 & -.2 & 93.90 & 99.04 & -.14 & 65.52 & 99.06 \\
\hline 136 & 238.095 & 12.983 & & & 128 & 6.615 & 161.527 & 78.289 & -.0 & & & & -.27 & 12 & .37 \\
\hline 137 & 244.560 & 12.800 & 1.7 & .8288 & 149 & 6.510 & 163.412 & 78.887 & 11 & -.2 & 101.75 & 1.84 & -.10 & 03 & .03 \\
\hline 138 & 250.946 & 12.632 & 2.257 & .8288 & 170 & 6.443 & 165.130 & 79.452 & -.014 & -.168 & 103.20 & 103.33 & -.13 & 67.74 & 3.57 \\
\hline 139 & 257.248 & 12.454 & 2.828 & .8288 & 73.191 & 6.366 & 166.868 & 79.987 & -.010 & -.0 & 104.75 & 104.91 & -.15 & 68.49 & 105.22 \\
\hline 140 & 263.551 & 12.271 & 3.502 & .8288 & 73.212 & 6.491 & 168.526 & 80.501 & -.020 & & 106.27 & .59 & -.31 & 69.13 & 106.87 \\
\hline 141 & 269.931 & 12.082 & 4.300 & .9288 & 234 & 6.499 & 170.427 & 81.002 & $\because 0$ & & $108 \cdot 15$ & & -.25 & 02 & . 92 \\
\hline 142 & 276.292 & 11.887 & 5.224 & .8288 & 73.255 & 6.457 & 172.202 & 81.483 & -.028 & .540 & 103.98 & 110.38 & -.37 & 70.75 & .95 \\
\hline 143 & 282.595 & 11.688 & $\epsilon .278$ & .3288 & 73.277 & 6.377 & 174.026 & 81.944 & -.033 & .8 & $111.9 E$ & 112.48 & -.46 & 71.53 & 113.19 \\
\hline 144 & 288.813 & 11.484 & 7.464 & .8287 & .299 & 6.300 & 175.873 & 82.383 & -.039 & 1.322 & 114.09 & 11 & -.55 & 72.33 & 115.63 \\
\hline 236 & 83.132 & 6.673 & 0.000 & .9213 & .706 & 1.056 & 117.630 & 40.313 & 0.000 & 0. & 83.92 & .93 &. .01 & 59.63 & .92 \\
\hline 237 & . 995 & .653 & 0 & & 07 & .67 & .126 & 40.809 & & & 92 & & -.05 & & 92 \\
\hline 23 & 8 & 16 & 0.0 & .9 & 78 & 1.057 & 728 & 301 & 0 & & .04 & 01 & .03 & 59.60 & 84.04 \\
\hline 239 & 85.723 & $16 . E 14$ & 0.000 & .9213 & 72.711 & .679 & 119.024 & 41.786 & 0.000 & 0. & 83.83 & 84.06 & -.27 & 59.32 & 83.83 \\
\hline 240 & 86.395 & 16.599 & 0.000 & . 9213 & 72.712 & .675 & 119.482 & 42.159 & 0.000 & 0.000 & 33.93 & 84.09 & -.20 & 59.35 & 83.93 \\
\hline 201 & 86.763 & 16.591 & 0.000 & .9213 & 72.712 & 2.94 & 1 & 42. & 0.0 & & 84.32 & 84.1 & .25 & & 84.32 \\
\hline 24 & 87.064 & 16.584 & 0.0 & - 9 & 13 & 670 & 11 & & 0 & & .04 & 12 & -.10 & 59.40 & 84.04 \\
\hline 24 & 87.870 & 16.566 & 0.00 & .9213 & .715 & .950 & 120.662 & 42.966 & 0.0 & 0. & 84.33 & 8 & .20 & 59.63 & 84.33 \\
\hline 243 & 88.931 & 16.542 & 0.000 & .9213 & 72.717 & 1.178 & 121.183 & 43.537 & 0.000 & 0.000 & $8+.28$ & $8+.2$ & .07 & 59.48 & 84.28 \\
\hline 202 & 90.366 & 16.509 & 0.0 & .9213 & 72.719 & 4.29 & 122.177 & 44.295 & 0.000 & 0.0 & 84.53 & 84.2 & .28 & 59.62 & 84.53 \\
\hline 203 & 66 & 16.400 & 0.0 & & .729 & 5.333 & 834 & 46.726 & 0.0 & & 84.78 & & .28 & & 84.78 \\
\hline 204 & 101.406 & 16.258 & 0.0 & . 3213 & 72.742 & 7.163 & 128.059 & 49.654 & 0.000 & 0.0 & 55.10 & 84.89 & .26 & 59.34 & 95.10 \\
\hline 205 & 108.461 & 16.098 & 0.000 & .9213 & 72.758 & 6.966 & 131.385 & 52.671 & 0.000 & 0.000 & 85.43 & 85.28 & .18 & 59.20 & 85.43 \\
\hline 206 & 115.393 & 15.934 & 0.000 & .9213 & 72.774 & 6.82 & 174.400 & 55.358 & 0.000 & 0.0 & 85.79 & 85.70 & .11 & 59.12 & 85.79 \\
\hline 207 & 122.1 & 15.785 & 0.0 & & 790 & 6.6 & .126 & 57. & 0.0 & 0 . & 86.18 & 86 & Ba & 12 & 86.18 \\
\hline 208 & 128.738 & 15.034 & 0.00 & .9213 & 72.807 & 6.565 & 139.549 & 59.343 & 0 & & .51 & & -.07 & 09 & 85.51 \\
\hline 209 & 135.238 & 15.485 & 0.000 & .3213 & 72.823 & 6.479 & 141.825 & 61.741 & 0 & -。 & 86.92 & 87.03 & -.13 & 59.17 & 86.92 \\
\hline 210 & 141.629 & 15.337 & .00 & .9213 & 72.840 & 6.35 & 143.934 & 63.449 & 0.0 & & $87 \cdot 35$ & 87.5 & -.19 & 28 & 87.35 \\
\hline 211 & 147.902 & 15.192 & .0 & & & 6.2 & 145.949 & 64.987 & 0.0 &.- & 87.87 & 88.03 & -.18 & & 37.87 \\
\hline 212 & 154.093 & 15.048 & .005 & .9213 & $72.87+$ & 6.190 & 147.768 & 66.386 & 0 &.- & 80.32 & 88.56 & -.27 & 59.66 & 88.32 \\
\hline 21 & 160.34 & 14.902 & .009 & .9213 & 72.892 & 6.108 & 149.670 & 67.690 & 0 & -. & 83.97 & 89.14 & -.19 & 60.00 & 88.97 \\
\hline 214 & $165.37 d$ & 14.761 & .016 & .9213 & 72.909 & 6.042 & $151.4 \pi 9$ & 60.856 & 0.000 & -.0 & 89.58 & 89.73 & -.16 & 60.33 & 89.58 \\
\hline 215 & 172.363 & 14.620 & .027 & .9213 & 72.926 & 6.011 & 153.069 & 69.933 & 0.000 & -.0 & 90.21 & 90.35 & -.16 & 57 & 90.21 \\
\hline 21 & .276 & 14 & & 13 & 943 & 5.914 & 638 & 70.926 & 0.0 & & $y 0.82$ & 00 & -.20 & 93 & 30.83 \\
\hline 217 & 184.114 & 14.340 & .069 & .9213 & 72.961 & 5.851 & 156.153 & 71.845 & -.001 & -.0 & 91.46 & 91.69 & -.25 & 61.32 & 91.47 \\
\hline 218 & 189.882 & 14.201 & .104 & .9213 & 72.970 & 5.790 & 157.680 & 72.698 & -.001 & -.052 & 92.19 & 92.41 & -.24 & & $9 ? .21$ \\
\hline 219 & 195.603 & 14.062 & .153 & .9213 & 72.995 & 5.767 & 159.243 & 73.496 & -.001 & -.0 & 93.01 & 93.17 & -.17 & & 93.03 \\
\hline 220 & 202.405 & 13.896 & .233 & .9213 & 73.016 & 7.033 & 160.816 & $7+.388$ & -.002 & -.0 & 93.74 & 94.13 & -.41 & 62.55 & 93.78 \\
\hline 221 & 209.358 & 13.723 & .347 & .9213 & 73.037 & 6.971 & 162.868 & 75.243 & -.003 & -.0 & 95.04 & 95.18 & -.15 & 63.39 & 95.10 \\
\hline 222 & 216.234 & 13.551 & .500 & .9213 & .059 & 6.845 & 164.767 & 76.038 & -.003 & -.0 & 96.25 & & -.05 & 11 & 96.33 \\
\hline 22 & 222.998 & 13.378 & .599 & .9213 & 73.080 & 6.752 & 166.481 & 76.777 & -.005 & -.021 & $97 \cdot 34$ & 97.48 & -.15 & 64.67 & 97.45 \\
\hline 224 & 227.651 & 13.206 & .351 & .9213 & 73.101 & 6.626 & 168.233 & 77.464 & -.006 & .023 & 98.54 & 98.73 & -.19 & 65.30 & 9.8 .68 \\
\hline 20 & 236.231 & 13.032 & 1.266 & .9213 & 73.122 & 6.514 & 169.990 & 78.111 & -.007 & & 49.81 & 100.04 & -.24 & 95 & 100.00 \\
\hline 226 & 242.764 & 12.857 & 1.652 & .9213 & 73.143 & 6.534 & 171.848 & 78.723 & -.009 & .183 & 101.25 & 101.44 & -.19 & 66.73 & 101.51 \\
\hline
\end{tabular}


Table 5. Representation of present $\mathrm{C}_{\sigma}$ data

\begin{tabular}{|c|c|c|c|c|c|}
\hline Run & Wt. & $\mathrm{T}, \mathrm{K}$ & $\mathrm{J} / \mathrm{mol} / \mathrm{K}$ & Calcd. & Pcnt. \\
\hline 101 & 0.000 & 81.053 & 82.350 & 83.798 & -1.13 \\
\hline 102 & 1.000 & 81.756 & 33.610 & 93.838 & -.27 \\
\hline 103 & 1.000 & 82.677 & 83.650 & 83.890 & -.29 \\
\hline 236 & 1.000 & 83.132 & 83.923 & 83.915 & .00 \\
\hline 104 & 0.000 & 83.593 & 83.310 & 83.942 & -.75 \\
\hline 237 & 1.000 & 83.995 & 93.920 & 83.965 & -.05 \\
\hline 105 & 1.000 & 84.568 & $83.8+0$ & 83.997 & -.19 \\
\hline 238 & 1.000 & 84.860 & 84.040 & 34.014 & .03 \\
\hline 106 & 1.000 & 85.598 & 83.950 & 84.055 & -.13 \\
\hline 239 & 1.000 & 85.723 & 83.837 & 94.062 & -.28 \\
\hline 240 & 1.000 & 86.395 & 83.937 & 84.100 & -.20 \\
\hline 107 & 1.000 & 86.622 & 84.290 & 84.113 & .21 \\
\hline 201 & 1.000 & 86.763 & 84.320 & 84.121 & .24 \\
\hline 108 & 1.000 & 86.036 & 83.813 & 34.125 & -.37 \\
\hline 241 & 1.000 & 87.064 & 84.040 & 84.137 & -.12 \\
\hline 109 & 1.000 & 87.856 & 84.150 & 84.182 & -.04 \\
\hline 242 & 1.000 & 87.870 & 84.330 & $8+.183$ & .18 \\
\hline 110 & 1.000 & 88.871 & 84.170 & 84.238 & -.08 \\
\hline 243 & 1.000 & 88.931 & 84.280 & 84.242 & .05 \\
\hline 111 & 1.000 & 89.879 & 84.490 & 84.295 & .22 \\
\hline 202 & 1.000 & 90.365 & 84.530 & 84.322 & .25 \\
\hline 112 & 1.000 & 91.366 & 84.540 & 84.378 & .19 \\
\hline 113 & 1.000 & y3.321 & 84.730 & 34.487 & .29 \\
\hline 203 & 1.000 & 95.166 & 84.780 & 84.589 & .23 \\
\hline 114 & 1.000 & 95.750 & 84.730 & 84.622 & .13 \\
\hline 115 & 1.000 & 99.797 & 84.940 & 84.848 & .11 \\
\hline 204 & 1.000 & 101.406 & 85.100 & 84.938 & . 19 \\
\hline 116 & 1.000 & 104.646 & 85.250 & 35.121 & .15 \\
\hline 205 & 1.000 & 108.461 & 85.437 & 85.338 & .11 \\
\hline 117 & 1.000 & 110.300 & 85.530 & 85.444 & .10 \\
\hline 206 & 1.000 & 115.393 & 85.790 & 85.743 & .06 \\
\hline 113 & 1.000 & 116.889 & 85.810 & 85.832 & -.03 \\
\hline 207 & 1.000 & 122.132 & 86.180 & 86.151 & .03 \\
\hline 119 & 1.000 & 124.009 & 86.200 & 86.269 & -.08 \\
\hline 208 & 1.000 & 128.738 & 86.510 & 36.572 & -.07 \\
\hline 120 & 1.000 & 131.003 & 86.690 & 86.721 & -.04 \\
\hline 209 & 1.000 & 135.238 & 86.920 & 87.008 & -.10 \\
\hline 121 & 1.000 & 137.870 & $87.1 \angle 0$ & 87.193 & -.06 \\
\hline 210 & 1.000 & 141.629 & 87.350 & 87.465 & -.13 \\
\hline 122 & 1.000 & 145.757 & 87.680 & 87.775 & -.11 \\
\hline 211 & 1.000 & 147.902 & 87.870 & 87.942 & -.08 \\
\hline 123 & 1.000 & 152.350 & $88.1 \in 0$ & 88.300 & -.16 \\
\hline 212 & 1.000 & 154.093 & 88.320 & 88.446 & -.14 \\
\hline 124 & 1.000 & 158.858 & 88.770 & 88.858 & -.10 \\
\hline 213 & 1.000 & 160.343 & 88.970 & 88.990 & -.02 \\
\hline 125 & 1.000 & 165.298 & 89.300 & 89.451 & -.17 \\
\hline 214 & 1.000 & 166.378 & 89.580 & 89.555 & .03 \\
\hline 126 & 1.000 & 171.647 & 90.110 & 90.081 & .03 \\
\hline 215 & 1.000 & 172.363 & 90.210 & 90.155 & .06 \\
\hline 216 & 1.000 & 178.276 & 90.820 & 90.790 & .03 \\
\hline 127 & 1.000 & 179.354 & 90.900 & 90.911 & -.01 \\
\hline 217 & 1.000 & 154.114 & 91.460 & 91.462 & -.00 \\
\hline 128 & 1.000 & 185.534 & 91.670 & 91.632 & .04 \\
\hline 213 & 1.000 & 189.882 & 92.197 & 92.172 & .02 \\
\hline 129 & 1.000 & 191.643 & 92.480 & 92.398 & .09 \\
\hline 21, & 1.000 & 195.603 & 93.010 & 92.924 & .09 \\
\hline 130 & 1.000 & 197.686 & 93.210 & 93.211 & -.00 \\
\hline 220 & 1.000 & 202.405 & 93.740 & 93.885 & -.15 \\
\hline 131 & 1.000 & 204.154 & 94.130 & 94.144 & -.02 \\
\hline 221 & 1.000 & 209.358 & 95.040 & 94.946 & .10 \\
\hline 132 & 1.000 & 211.041 & 95.390 & 35.215 & .18 \\
\hline 222 & 1.000 & 216.234 & 96.250 & 96.078 & .18 \\
\hline 133 & 1.000 & 217.854 & 96.430 & 96.357 & .08 \\
\hline 223 & 1.000 & 222.998 & 97.347 & 97.275 & .07 \\
\hline 134 & 1.000 & 224.592 & 97.550 & 97.570 & -.02 \\
\hline 224 & 1.000 & 229.651 & 98.540 & 98.539 & .00 \\
\hline 135 & 1.000 & 231.245 & 98.900 & 98.855 & .05 \\
\hline 225 & 1.000 & 236.231 & 99.819 & 99.875 & -.07 \\
\hline 136 & 1.000 & 238.095 & 100.160 & 100.270 & -.11 \\
\hline 226 & 1.000 & 242.764 & 101.250 & 101.291 & -.04 \\
\hline 137 & 1.000 & 244.560 & 101.750 & 101.696 & .05 \\
\hline 133 & 1.000 & 250.945 & 103.200 & 103.193 & .01 \\
\hline 139 & 1.000 & 257.248 & 104.750 & 104.759 & .01 \\
\hline 140 & 1.000 & 263.551 & 106.270 & 106.415 & -.14 \\
\hline 141 & 1.000 & 269.931 & 108.150 & 108.184 & -.03 \\
\hline 142 & 1.000 & 276.292 & 109.987 & 110.042 & -.06 \\
\hline 143 & 1.000 & 282.595 & 111.963 & 111.975 & -.01 \\
\hline 144 & 1.000 & 288.613 & 114.090 & 113.970 & .11 \\
\hline$N P=$ & $78, \quad \mathrm{RM}$ & $C T=$ & & & \\
\hline
\end{tabular}


Table 6. Representation of all $\mathrm{C}_{\sigma}$ data

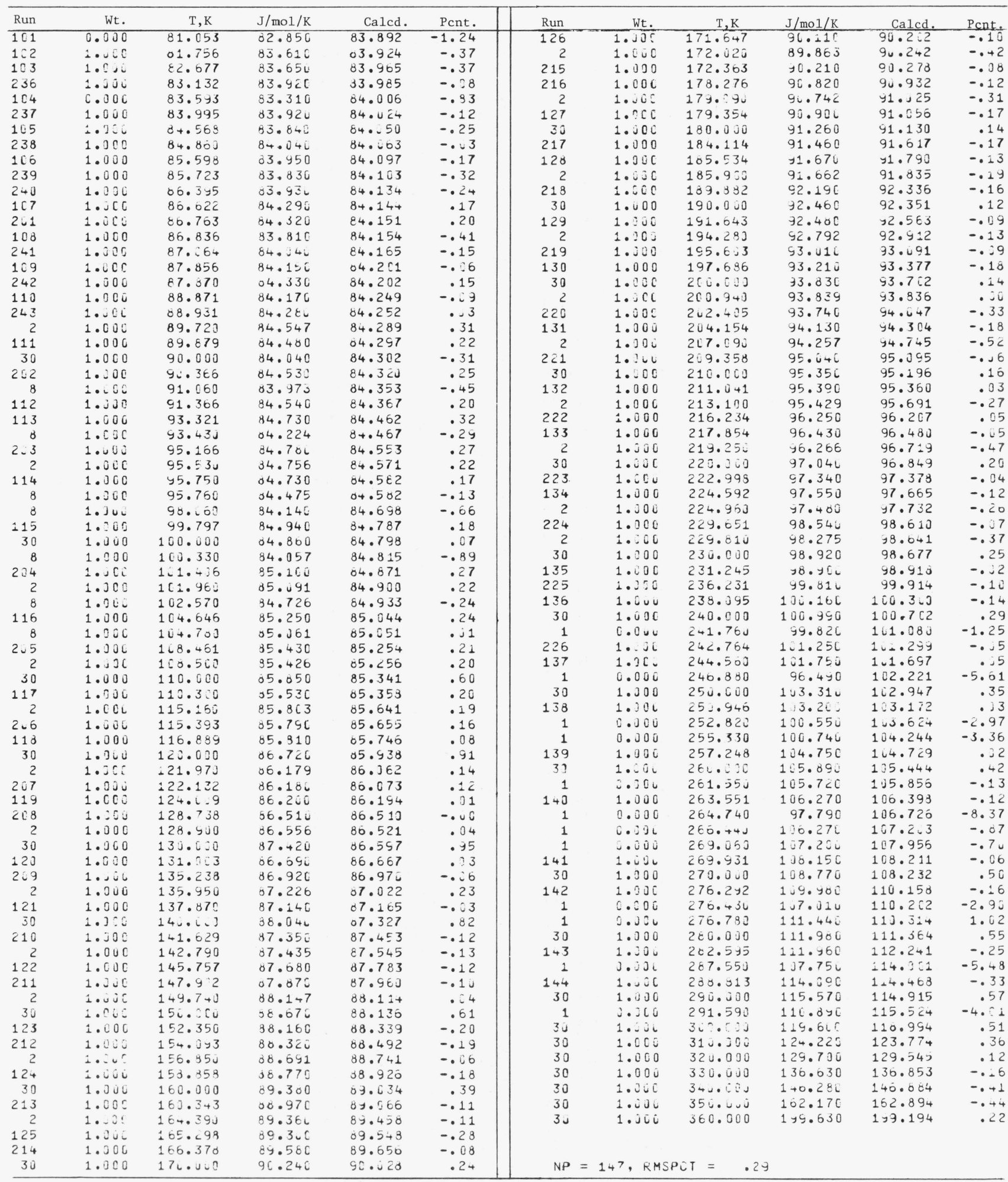


Table 7. Experimental data for compressed liquid

\begin{tabular}{|c|c|c|c|c|c|c|c|c|c|c|c|c|}
\hline no. & $\begin{array}{l}\mathrm{T}_{\mathrm{av}}, \\
\mathrm{K}\end{array}$ & $\begin{array}{c}\rho, \\
\mathrm{mol} / \mathrm{L}\end{array}$ & $\begin{array}{r}\text { P, } \\
\text { bar }\end{array}$ & $\begin{array}{l}\mathrm{N}_{\mathrm{b}}, \\
\mathrm{mol}\end{array}$ & $\begin{array}{l}\mathrm{V}_{\mathrm{b}}, \\
\mathrm{cm}^{3}\end{array}$ & $\begin{array}{c}\Delta \mathrm{T}, \\
\mathrm{K}\end{array}$ & $\begin{array}{l}\mathrm{Q} / \Delta \mathrm{T}, \\
\mathrm{J} / \mathrm{K}\end{array}$ & $\begin{array}{l}\mathrm{C}_{0}, \\
\mathrm{~J} / \mathrm{K}\end{array}$ & $\begin{array}{l}\text { Corr., } \\
\mathrm{J} / \mathrm{mol} / \mathrm{K}\end{array}$ & $\begin{array}{l}\mathrm{C}_{\mathrm{v}}, \mathrm{J} / \mathrm{m} \\
\text { Expt } 1 .\end{array}$ & Calcd. & $\begin{array}{c}\text { Diff. } \\
\%\end{array}$ \\
\hline 145 & 296.740 & 11.240 & 20.564 & .0290 & 73.340 & 3.531 & $14 b .55$ & 82.92 & -1.75 & 74.25 & 74.16 & .12 \\
\hline 146 & 361.507 & 11.283 & 45.144 & .8280 & 73.385 & 6.057 & 146.14 & 83.24 & -1.76 & $74 \cdot \mathrm{cu}$ & $74 \cdot 9+$ & $-1 \cdot 00$ \\
\hline 147 & 307.514 & 11.274 & $75 . y 45$ & .8256 & 73.441 & $\bar{c} .02 \bar{c}$ & $147 \cdot+4$ & 83.62 & -1.79 & 75.28 & $75.9+$ & -.87 \\
\hline 148 & 313.49 & $11 \cdot \angle 65$ & 106.338 & .8280 & 73.497 & 5.959 & 148.05 & $8+.0 \mathrm{~J}$ & -1.82 & 76.27 & 76.96 & -.91 \\
\hline 149 & $319.3=0$ & 11.257 & 130.202 & $.323 C$ & 73.553 & 5.914 & $1+y \cdot 90$ & 84.36 & -1.85 & 77.31 & 77.59 & -.89 \\
\hline 150 & 325.273 & 11.248 & 165.870 & .8200 & 73.609 & 5.857 & 150.96 & 04.71 & -1.88 & 78.14 & 79.03 & $-1 \cdot 14$ \\
\hline 151 & 351.118 & 11.235 & 195.101 & $.827 y$ & $7 \overline{3} .005$ & 5.314 & $152 \cdot 2 \bar{c}$ & $85 .\llcorner 5$ & $-1 \cdot 91$ & 79.22 & $8 C \cdot 68$ & -1.39 \\
\hline 152 & $325 \cdot 9+4$ & $\therefore 1.231$ & 224.054 & .8279 & $73 \cdot 721$ & $5.75 i$ & $153 .+0$ & 85.38 & -1.94 & $8 \iota .26$ & 81.13 & -1.08 \\
\hline 001 & $278.5 \geq 2$ & 11.949 & 35.444 & .0750 & 73.294 & 6.106 & 145.44 & 81.65 & -2.35 & 70.70 & 71.51 & -1.03 \\
\hline $8 \div 2$ & 284.558 & 11.938 & 69.935 & .8758 & 73.356 & 6.45 & 146.75 & 82.03 & -2.09 & 71.75 & $72 \cdot 40$ & -.90 \\
\hline 013 & 290.462 & $11 \cdot 720$ & $1.5 \cdot c+t$ & .8758 & 73.413 & $5 \cdot 9 y 5$ & $1+8 \cdot 13$ & $82 \cdot 53$ & -2 & 72.82 & $73 \cdot 31$ & -.68 \\
\hline $8: 4$ & 296.874 & 11.917 & 145.139 & .8757 & $73 .-85$ & $7 \cdot 017$ & $149 \cdot 01$ & 82.93 & -2.16 & 73.58 & 74.33 & -.48 \\
\hline $8 j 5$ & 203.745 & $11 \cdot 9: 5$ & $180 \cdot 2 y 9$ & .8757 & 73.557 & 6.929 & 151.19 & 83.33 & -2.20 & 75.23 & 75.46 & -.30 \\
\hline $8 \subset 6$ & $31<.5<4$ & 11.894 & $227 \cdot 186$ & .8757 & 73.629 & 6.867 & 152.74 & 83.81 & $-2 \cdot 24$ & 76.47 & 76.60 & -.18 \\
\hline $8<7$ & $317 \cdot 245$ & $11.00 \bar{c}$ & 207.113 & .0757 & 73.701 & 6.7 y 6 & 154.24 & 84.23 & $-2 \cdot 28$ & 77.67 & 77.77 & -.13 \\
\hline 810 & 322.552 & 11.873 & $\angle 90.351$ & .8757 & 73.757 & $4.0 \cup 8$ & 155.49 & $84.5 j$ & -2.32 & 78.69 & 78.71 & -.02 \\
\hline 228 & 250.127 & 12.573 & 27.046 & .9205 & 73.214 & 2.809 & $144 \cdot 21$ & 79.89 & -2.36 & 67.50 & 68.52 & -1.52 \\
\hline 229 & 258.803 & $12.5 E O$ & 47.302 & .0205 & 73.245 & $2.7, \overline{3}$ & $1+4.95$ & $0 u \cdot 12$ & $-2 \cdot 38$ & 60.14 & 68.88 & $-1 \cdot 23$ \\
\hline 236 & $262 . y 50$ & $12.56 \mathrm{~L}$ & 76.936 & $.52-5$ & $73 \cdot<92$ & 5.389 & 146.02 & 80.45 & $-2 \cdot 40$ & 68.83 & 69.42 & -.86 \\
\hline 201 & 268.252 & $-2 \cdot 5-9$ & 112.510 & $.92 j 5$ & 73.353 & 5.356 & $147 \cdot 34$ & 85.87 & $-2 \cdot 4+$ & 09.17 & 70.15 & -.54 \\
\hline 232 & 273.524 & 12.539 & 153.660 & . $92 \cup 5$ & 73.414 & 5.301 & 148.46 & 61.28 & $-2 \cdot 48$ & 70.50 & 70.89 & -.55 \\
\hline 233 & 278.769 & 12.528 & $191 \cdot 247$ & $.92,5$ & 73.475 & 5.207 & 149.64 & 01.67 & -2.52 & 71.33 & 71.06 & $-\bullet+6$ \\
\hline 234 & 283.578 & 12.510 & 228.3 .6 & .9205 & $75 \cdot 535$ & 5.237 & $15 \mathrm{c} \cdot 91$ & 82.04 & -2.55 & 72.26 & $72 \cdot+4$ & -.25 \\
\hline 235 & 289.142 & $1<\cdot \partial C 7$ & 254.777 & $.92 \cup 5$ & $75 \cdot 590$ & 5.195 & 152.30 & $82 \cdot 41$ & $5 y$ & $73 \cdot 34$ & 24 & .13 \\
\hline 9ट1 & 238.172 & 13.455 & 28.490 & .9554 & 73.158 &. .296 & 4.06 & 78.33 & -2 & 66.22 & 41 & -.29 \\
\hline 902 & 242.033 & 13.449 & 67.540 & • ง5:4 & $73 \cdot 215$ & $5 \cdot 194$ & 144.57 & 75.73 & -2.64 & $66 \cdot<8$ & 66.95 & $-i \cdot 32$ \\
\hline So 3 & 248.402 & 13.036 & 114.060 & . 9554 & 73.284 & $0 .+20$ & $1+5.97$ & 79.23 & -2.69 & 67.18 & 67.63 & -.67 \\
\hline 904 & 254.481 & $-3 \cdot 5<3$ & 163.629 & - 3553 & 73.359 & 0.049 & $147 \cdot 47$ & 79.75 & -2.74 & $68 \cdot 15$ & 68.38 & -.33 \\
\hline 905 & $260.3<9$ & $13 \cdot 110$ & 212.165 & .9553 & 73.433 & 5.992 & 148.90 & 80.24 & -2.79 & 69.08 & 69.16 & -.12 \\
\hline 916 & 205.728 & $12 \cdot y 97$ & 255.975 & - 9553 & 70.531 & 4. गy3 & 150.36 & $8: .67$ & -2.84 & $70 \cdot 11$ & 99 & .31 \\
\hline 907 & 270.590 & $12 \cdot 987$ & 205.110 & •95うこ & 73.563 & $4 . y 32$ & 251.61 & 81.55 & -2 & $70 \cdot 98$ & 7.57 & .57 \\
\hline $3<1$ & $215.32+$ & 10.015 & $35 \cdot 154$ & 52 & $7 \overline{3} \cdot 597$ & 3.8 & 73 & 70 & -2 & $64 \cdot .2$ & 22 & -.31 \\
\hline 302 & 220.658 & 13.606 & $72.87 \mathrm{C}$ & - 9952 & 73.148 & 3.5 & 1 & 7 & -2 & 64.05 & 60 & -.86 \\
\hline 303 & $224 \cdot+36$ & 13.596 & 109.774 & .9952 & $73.20 \mathrm{v}$ & 3.048 & 143.87 & 76.93 & $-3 . u v$ & 64.27 & 64.98 & -1.11 \\
\hline 3.4 & 220.190 & $13.5 E 6$ & $14 c \cdot z O B$ & - y952 & 73.251 & 3.833 & 144.90 & $77 \cdot 32$ & $-3.0+$ & $5+.87$ & 38 & -.79 \\
\hline $3: 5$ & 231.931 & 13.577 & 182.282 & .9952 & $73 \cdot 0 \cup 2$ & 3.791 & $1+5.89$ & 77.69 & $-3 \cdot 07$ & 65.45 & 65.79 & -.51 \\
\hline $3 \div 6$ & 235.624 & 13.567 & 217.041 & .9952 & 73.352 & 3.753 & 146.90 & 78.05 & -3.11 & 66.07 & 6.20 & -.19 \\
\hline 367 & 239.291 & 13.558 & 252.530 & .9952 & 73.403 & 3.734 & 147.87 & 78.40 & -3.15 & 66.66 & 62 & .05 \\
\hline $4: 1$ & 188.870 & it. cy y & $4 \ldots 935$ & 1. .439 & $73 . \pm 6$ & $3.75=$ & $1+0 \cdot 2 i$ & 72.55 & $-\overline{3} \cdot 32$ & $61 \cdot 48$ & 61.89 & -.67 \\
\hline $4 \sqrt{2}$ & 192.581 & $14 . \angle O E$ & $8 E \cdot 5.2$ & $1 \cdot 1+39$ & 73.073 & 3.906 & 241.10 & 73.39 & -3.37 & 61.84 & 2.18 & -.54 \\
\hline 403 & 196.572 & 14.273 & 132.941 & $1.0+35$ & $7 \geq .132$ & $3.93 c$ & 142.15 & 73.63 & $-3 \cdot 41$ & 62.23 & 62.48 & -.40 \\
\hline 464 & $2 \mathrm{LO} \cdot 428$ & $14 \cdot 262$ & 178.490 & 1.3438 & $73 \cdot 191$ & 5.899 & 143.28 & $7+\cdot 1+$ & -3.40 & 62.78 & 62.80 & -.04 \\
\hline $4 i 5$ & $24 \cdot 255$ & 14.252 & 222.340 & $1 .+38$ & 73.25 & 3.864 & 144.32 & $7 \rightarrow 062$ & -3.51 & $63 \cdot<7$ & .13 & - 21 \\
\hline 466 & $6.7 \cdot 8=2$ & $1+.239$ & 265.92 & $1 \cdot+38$ & 73.005 & 3.441 & 40 & 75.05 & -3 & .83 & 46 & \\
\hline 501 & $156 \cdot=2$ & 15.044 & 40.349 & 1.3971 & 72.928 & 3.807 & 137.04 & 67.00 & -3 & 60.68 & 60.02 & .09 \\
\hline $5<2$ & $10 \mathrm{~J} \cdot 050$ & $1=0.82$ & $104.65 y$ & $1.0 y 71$ & 72.592 & 3.629 & $138 \cdot 16$ & 57.75 & -3.82 & $63 \cdot 36$ & $60 \cdot 20$ & .26 \\
\hline 5,3 & 264.253 & 15.018 & 158.589 & 1.0971 & $73.05+$ & $3.5 y 2$ & & 68. & -3 & 60.80 & 8.38 & 68 \\
\hline $5 r_{3}$ & $167 \cdot 3=2$ & $1 E .005$ & 211.15 & 1.0971 & $73 \cdot 115$ & 3.503 & $1+5.52$ & $69 \cdot 12$ & -3.93 & 01.15 & 60.58 & 93 \\
\hline & 171.313 & 14.992 & 262.030 & 1.0971 & 73.177 & 3.528 & 71 & 09 & -3.99 & .00 & 78 & 33 \\
\hline 601 & $120 \div 2$ & 15.731 & 44.790 & $=1+50$ & 72.84 .3 & $\bar{c} \cdot 6+\bar{c}$ & 132.33 & 59.12 & $-4 \cdot 12$ & $5 j .78$ & $59 \cdot 12$ & 1.11 \\
\hline $6: 2$ & $1 \geq 9.03 ?$ & 15.720 & 94.654 & $1 \cdot 1+j 8$ & $72 \cdot 891$ & c. 521 & 133.49 & 59.93 & -4.17 & 60.62 & 59.10 & 1.44 \\
\hline $0: 3$ & $131.6 y 9$ & $1 \overline{1} \cdot T \cdot 8$ & $: 44.995$ & 1.1450 & $72 .=42$ & 2.743 & 134.57 & 60.73 & $-4 \cdot 22$ & $6 i \cdot 22$ & 59.21 & 1.67 \\
\hline 604 & 134.428 & 15.697 & $195.78 y$ & 1.1458 & 72.996 & 2.724 & 135.64 & 61.51 & -4.28 & $60 \cdot-1$ & 59.28 & 1.80 \\
\hline $6: 5$ & $1 \geq 7 \cdot 1: 5$ & 15.085 & $\angle 45.67 ?$ & $1 \cdot 1+50$ & $73 \ldots+8$ & 2.701 & 136.00 & $62 \cdot 26$ & -+.34 & 60.60 & 59.35 & $2 \cdot 36$ \\
\hline 701 & 100.334 & 26.319 & $\rightarrow \varepsilon \cdot<27$ & 1.1877 & 76.779 & $2 \cdot 4 c \overline{3}$ & $1<6$. & 49.17 & -4.32 & 60.49 & 59.14 & 2.23 \\
\hline $7: 2$ & 102.729 & $16 \cdot 3 \cdot 7$ & 104.627 & 1.1076 & 72.830 & 2.373 & $127 \cdot 62$ & 50.24 & -4.39 & 60.76 & 59.11 & 2.73 \\
\hline 703 & 105.095 & 16.295 & 159.753 & 1.1876 & $72 \cdot 001$ & 2.365 & 128.83 & $51 \cdot 27$ & $-4 \cdot 45$ & 60.00 & 59.08 & $2 \cdot 91$ \\
\hline $7: 4$ & 117.444 & 16.284 & 213.892 & 1.1570 & $7 c .93 i$ & 2.345 & 130.05 & 52.25 & -4.52 & 60.99 & 59.07 & 3.15 \\
\hline
\end{tabular}


Table 8. Derived experimental and calculated $C_{p}, J / m o l / K$

\begin{tabular}{|c|c|c|c|c|c|c|c|}
\hline \multirow{2}{*}{$\begin{array}{l}\text { Run } \\
\text { no. }\end{array}$} & \multicolumn{2}{|c|}{$\mathrm{C}_{\mathrm{p}}, \mathrm{J} / \mathrm{mol} / \mathrm{K}$} & \multirow{2}{*}{$\begin{array}{c}\text { Diff., } \\
\%\end{array}$} & \multirow{2}{*}{$\begin{array}{l}\text { Run } \\
\text { no. }\end{array}$} & \multicolumn{2}{|c|}{$\mathrm{C}_{\mathrm{p}}, \mathrm{J} / \mathrm{mol} / \mathrm{K}$} & \multirow{2}{*}{$\begin{array}{c}\text { Diff., } \\
\%\end{array}$} \\
\hline & Expt1. & Calcd. & & & Expt1. & Calcd. & \\
\hline 145 & 118.54 & 118.45 & .37 & 906 & 100.91 & 100.69 & .21 \\
\hline 240 & $+\div 7.12$ & $1+7.00$ & -.53 & 907 & 认兀1.jo & 160.97 & $\cdot+j$ \\
\hline $1+7$ & $-10.6 ?$ & 1.7 .29 & -.56 & 321 & 95.69 & 45.89 & -.21 \\
\hline 148 & 116.21 & $\$ 16.91$ & -.0 o j & $3 i 2$ & 95.33 & 92.93 & -.58 \\
\hline $14 \mathrm{y}$ & 115.99 & 116.65 & $-.5 y$ & $3 \mathrm{~J} 3$ & 95.27 & 95.99 & -.75 \\
\hline $25 j$ & 115.08 & 115.57 & -.77 & $3 j 4$ & 95.56 & 90.00 & -.54 \\
\hline 15: & $2.5 .7 i$ & $11 t .58$ & $-.7+$ & 315 & 95.02 & 96.19 & -.35 \\
\hline 152 & $115.8 ?$ & 126.66 & -.75 & $3: 5$ & 96.19 & 96.32 & -.13 \\
\hline Ł. 1 & $135.5 ?$ & 110.30 & -.66 & 307 & 90.51 & 96.48 & .04 \\
\hline 802 & 109.43 & 110.07 & -.59 & 401 & 91.47 & 91.88 & -.45 \\
\hline$c, 3$ & $\therefore 39.47$ & 1. & -.45 & $4: 2$ & 91.50 & 91.91 & -.37 \\
\hline Jat & 139.52 & $1: 9.97$ & -.02 & $+\square 3$ & 91.72 & 91.97 & -.27 \\
\hline 805 & 109.30 & i1i.1i & -.21 & +34 & 92.03 & 52.05 & -.03 \\
\hline $8 j 0$ & $11: .22$ & 110.35 & -.12 & 405 & 92.29 & 92.16 & .15 \\
\hline cu 7 & 11 . 0. & $21 j .7 i$ & -..y & $4 j 0$ & $y 2.65$ & $3 x .27$ & .41 \\
\hline$c=0$ & $11 \ldots 22$ & $21 \ldots, 14$ &.$-: 2$ & $5: 1$ & 88.58 & 88.53 & .96 \\
\hline 228 & $\therefore 3.10$ & $\ldots+11$ & -.99 & 502 & 83.70 & 08.50 & .18 \\
\hline 229 & 103.23 & 104.07 & -.01 & 503 & 08.99 & 03.58 & .46 \\
\hline $23 i$ & 125.47 & 1.4000 & -.57 & 204 & $0 y .19$ & 80.62 & .64 \\
\hline 201 & 105072 & $\therefore-40$ & -.36 & $5: 5$ & $09.5 i$ & 08.69 & .92 \\
\hline $63<$ & $\therefore 02.8 \mathrm{C}$ & 1.4 .21 &.$- ? 8$ & 6is 1 & $\delta E \cdot S i$ & 80.24 & .76 \\
\hline 233 & 104.36 & y y 4.3 & -.32 & 0.3 2 & 07.10 & 86.23 & .99 \\
\hline 234 & 104.44 & 104.62 & -.17 & 6) 3 & 87.24 & 86.24 & i. 15 \\
\hline$\angle 35$ & $1-5.2$. & 1.4 .91 & .39 & $6: 4$ & 87.38 & 86.25 & 1.32 \\
\hline y? & 99.75 & 99.95 & -.19 & 605 & 87.51 & 80.27 & 1.42 \\
\hline juc & 99.23 & प्र5.96 & -.60 & 701 & 00.05 & 84.70 & 1.57 \\
\hline 903 & 99.59 & $100 \cdot 04$ & -.45 & 702 & 86.35 & 84.69 & 1.92 \\
\hline yju- & 7 & $1 \ldots 2^{r}$ & -.23 & $7: 0$ & 06.46 & 04.69 & 2.05 \\
\hline Gos & $12 \ldots .35$ & $1 \ldots+3$ &.- .08 & 704 & 86.01 & 84.69 & 2.22 \\
\hline
\end{tabular}

Table 9. Reduced specific heats, $\left(\mathrm{C}_{\mathrm{v}}-\mathrm{C}_{\mathrm{v}}^{\mathrm{O}}\right), \mathrm{J} / \mathrm{mol} / \mathrm{K}$

\begin{tabular}{|c|c|c|c|c|c|c|}
\hline Run & $\mathrm{T}, \mathrm{K}$ & $\rho, \mathrm{mol} / \mathrm{L}$ & $\mathrm{C}_{\mathrm{v}}$ & $\mathrm{C}_{\mathrm{v}}^{\mathrm{O}}$ & $\mathrm{C}_{\mathrm{v}}-\mathrm{C}_{\mathrm{v}}^{\mathrm{O}}$ & $\left(C_{v}-C_{v}^{O}\right) / R$ \\
\hline 1 & $294.15 i$ & 11.303 & 73.68 & 54.08 & 9.06 & $1 . c 83$ \\
\hline $1+5$ & ¿GE.740 & $12 . \angle 90$ & 74.25 & $65 .: 9$ & $9 . j 6$ & 1.0 .9 \\
\hline 145 & $301.5 i 7$ & 11.283 & 74.20 & 00.12 & $8 . \cup 8$ & .971 \\
\hline 147 & 367.514 & $11.27+$ & 75.28 & 67.31 & 7.97 & .958 \\
\hline 148 & 313.479 & 11.265 & 76.27 & 68.49 & 7.78 & .935 \\
\hline $14 \mathrm{~J}$ & $3: 9.015$ & 11.257 & $77.3 i$ & 69.67 & 7.04 & .919 \\
\hline 150 & 325.273 & 11.248 & 78.14 & 76.04 & 7.36 & .878 \\
\hline 151 & $331.11 \hat{c}$ & $11.23 y$ & 79.22 & 72.01 & 7.21 & .068 \\
\hline 152 & 336.944 & 11.231 & 30.26 & 73.17 & 7.04 & .853 \\
\hline$z$ & $252 .+15$ & 12.591 & 66.90 & 56.69 & 10.27 & 1.235 \\
\hline 223 & 256.127 & 12.573 & 67.50 & $5 i \cdot 30$ & 13.12 & 1.217 \\
\hline 223 & 250.083 & 12.568 & 68.04 & 57.90 & 10.14 & 1.220 \\
\hline 230 & 262.333 & 12.560 & 68.83 & 50.66 & $1 \mathrm{~J} \cdot 17$ & 1.223 \\
\hline 231 & $z \in 8.252$ & 12.549 & 69.77 & 59.67 & 1). 1 ? & 1.215 \\
\hline 232 & 273.524 & 12.533 & 70.50 & 52.67 & 9.33 & 1.182 \\
\hline 233 & 278.769 & 12.528 & 71.33 & 61.68 & 9.65 & 1.160 \\
\hline 234 & 283.973 & 12.518 & $72 \cdot 26$ & 62.69 & 9.57 & 1.151 \\
\hline 235 & 289.142 & 12.5 .7 & $73 \cdot 34$ & $6 ? .70$ & 9.64 & 1.160 \\
\hline 3 & 212.389 & 10.035 & 63.80 & +9.73 & 14.15 & 1.702 \\
\hline 301 & 216.834 & 13.615 & 64.02 & 50.39 & 13.63 & 1.639 \\
\hline 362 & 220.058 & 13.600 & 64.05 & 51.04 & 23.01 & 1.565 \\
\hline $3+3$ & $224 .+36$ & 13.596 & 64.27 & 51.09 & 12.58 & 1.514 \\
\hline $3 i+$ & 228.198 & 13.536 & 04.97 & 52.34 & 12.53 & 1.507 \\
\hline 305 & 231.331 & 13.577 & 55.45 & 52.99 & 12.46 & 1.499 \\
\hline 325 & 235.624 & $13.56 ?$ & $66 . j 7$ & 53.64 & 12.43 & 1.494 \\
\hline 357 & $239.29:$ & 13.558 & 06.06 & 54.30 & 12.36 & 1.487 \\
\hline$\rightarrow$ & LOE. . 51 & $1+.318$ & 61.17 & 45.33 & 15.34 & 1.905 \\
\hline $4 i 1$ & 188.378 & 14.297 & 61.48 & 45.91 & 15.57 & 1.873 \\
\hline$+\div 2$ & 192.601 & 14.205 & 61.84 & $+6.4 y$ & 15.35 & 1.846 \\
\hline 4.3 & 196.572 & $1+.273$ & $02 .<3$ & 47.10 & 15.13 & 1.820 \\
\hline-64 & $2: 0 .+28$ & 14.252 & 62.78 & 47.71 & 15.07 & 1.813 \\
\hline 405 & $2 C+.255$ & 14.250 & 63.27 & $48 \cdot 32$ & 14.95 & 1.798 \\
\hline 406 & $267.35<$ & $1+.239$ & 63.83 & +8.36 & 14.93 & 1.795 \\
\hline 5 & 153.369 & $15 . i 67$ & 59.78 & 40.81 & 18.97 & 2.202 \\
\hline Ej1 & $156 . y=2$ & 15.344 & 60.68 & +1.31 & 18.77 & 2.257 \\
\hline 502 & 160.668 & 15.031 & 60.36 & 41.82 & 18.54 & 2.229 \\
\hline 543 & $16 L .253$ & $15 \cdot[10$ & 60.00 & 42.32 & 18.48 & 2.222 \\
\hline $50 \rightarrow$ & 167.012 & 15.005 & 61.15 & 42.82 & 18.33 & 2.204 \\
\hline 505 & 171.318 & 14.992 & 61.60 & +3.32 & 13.28 & 2.198 \\
\hline 5 & $123 . \mathrm{c} . \mathrm{c}$ & 15.752 & 59.22 & 30.73 & 22.79 & 2.742 \\
\hline Ei: & $126 .+12$ & 15.731 & 59.78 & 37.13 & 22.65 & 2.725 \\
\hline 6.2 & 129.00 & 15.720 & $00 .<2$ & 37.49 & 42.53 & 2.769 \\
\hline 603 & $131.5 y=$ & 15.708 & 60.22 & 37.86 & 22.36 & 2.689 \\
\hline 604 & 134.418 & 15.697 & 60.41 & 30.24 & 22.17 & 2.607 \\
\hline $6 L 5$ & 137.210 & 15.585 & $60.6 v$ & $30.6 i$ & 21.99 & 2.645 \\
\hline$?$ & $97.3 C E$ & $10 \cdot 3+0$ & 00.20 & $32.7 y$ & $\angle 7.4 C$ & 3.296 \\
\hline 701 & $10 \mathrm{C} .334$ & 15.319 & 60.49 & 33.21 & 27.28 & 3.282 \\
\hline 702 & $162.72 y$ & 10.337 & 00.76 & 33.59 & 27.17 & 3.260 \\
\hline $7: 3$ & $1: 5 .: 95$ & 16.295 & 00.85 & 33.97 & 26.88 & 3.233 \\
\hline iut & $1: 7 .+44$ & $15.28+$ & 63.99 & 34.34 & 26.65 & $3 .<40$ \\
\hline y & 273.712 & 11.967 & 69.91 & 60.71 & 9.20 & 1.107 \\
\hline ou 1 & $\angle 70.5 c c$ & 12.947 & 70.78 & 0.1 .65 & 9.13 & 1.099 \\
\hline 8.2 & 284.358 & 11.938 & 71.75 & 62.00 & 8.95 & 1.076 \\
\hline $3: 3$ & $250 .+02$ & 11.928 & 72.32 & 03.96 & 0.05 & 1.060 \\
\hline 804 & 296.874 & 11.917 & 73.98 & $5=.21$ & 8.77 & 1.055 \\
\hline 8.5 & 3.3 .743 & $1: .93 j$ & 75.23 & 66.57 & 8.66 & 1.042 \\
\hline 836 & 310.224 & 11.894 & 76.47 & 67.91 & 8.56 & 1.030 \\
\hline 057 & 317.245 & 11.832 & 77.67 & 69.24 & 8.43 & 1.013 \\
\hline ธง 8 & 322.550 & 11.873 & 78.69 & 76.30 & 8.39 & 1.069 \\
\hline j & $234.54:$ & 12.677 & 65.74 & 20.45 & 12.28 & $1.47^{7}$ \\
\hline 9.1 & 238.172 & 13.259 & 66.22 & $54 \ldots$ & 12.12 & 1.458 \\
\hline$y+2$ & $\angle 42.833$ & 13.045 & 06.20 & 54.94 & 11.34 & 1.364 \\
\hline 903 & 248.402 & 13.036 & 67.18 & 55.95 & 11.23 & $1.35 i$ \\
\hline$y=$ & $252 .+1$. & $13 .-23$ & 68.15 & 57.00 & $11 \cdot .9$ & 1.334 \\
\hline $9: 5$ & 260.329 & 13.210 & 09.08 & 58.17 & 20.91 & 1.313 \\
\hline Suo & 205.728 & 12.337 & 70.11 & 59.19 & 10.92 & 1.314 \\
\hline$y<7$ & $270.59 i$ & 12.987 & 70.98 & 52.11 & 10.87 & 1.307 \\
\hline
\end{tabular}

